\title{
DNA binding provides a signal for phosphorylation of the RNA polymerase II heptapeptide repeats
}

\author{
Scott R. Peterson, Arik Dvir, Carl W. Anderson, ${ }^{1}$ and William S. Dynan ${ }^{2}$ \\ Department of Chemistry and Biochemistry, University of Colorado, Boulder, Colorado 80309 USA; ${ }^{1}$ Biology Department, \\ Brookhaven National Laboratory, Upton, New York 11973 USA
}

\begin{abstract}
Isolated transcription complexes contain a protein kinase that phosphorylates the heptapeptide repeats of the carboxy-terminal domain (CTD) of the RNA polymerase II (RNAP II) large subunit in an apparently promoter-dependent manner. We now show that the essential features of this reaction can be reproduced in a reconstituted system containing three macromolecular components: a fusion protein consisting of the CTD of RNAP II fused to a heterologous DNA-binding domain, an activating DNA fragment containing the recognition sequence for the fusion protein, and a protein kinase that binds nonspecifically to DNA. This kinase closely resembles a previously known DNA-dependent protein kinase. Evidently, the association of the CTD with DNA provides a key signal for phosphorylation. There appears to be no absolute requirement for specific contacts with other DNA-bound transcription factors.
\end{abstract}

[Key Words: RNA polymerase II; phosphorylation; DNA-dependent protein kinase; heptapeptide repeats; transcription]

Received December 3, 1991; revised version accepted January 8, 1992.

Protein phosphorylation is an important mechanism for regulating eukaryotic cellular activity at both cytoplasmic and nuclear levels. The phosphorylation of transcription factors is one way in which protein kinases have been shown to directly influence the expression of genes in response to internal or external signals. Phosphorylation has been shown to result in the alteration of the function of several sequence-specific DNA-binding transcription factors at the level of DNA binding (Raychaudhuri et al. 1989; Boyle et al. 1991), transcriptional activation (Sorger and Pelham 1988), and nuclear translocation (Shirakawa and Mizel 1989).

In many instances, the precise contribution of phosphorylation to the regulation of the function of proteins in the transcriptional apparatus remains uncertain. One example is phosphorylation of the carboxy-terminal domain (CTD) of the largest subunit of RNA polymerase II (RNAP II). This domain contains an evolutionarily conserved heptapeptide sequence (Ser-Pro-Thr-Ser-Pro-SerTyr) that is tandemly repeated up to 52 times (Allison et al. 1985; Corden et al. 1985; for review, see Corden 1990). Because of the limitations of existing in vitro systems, much of our understanding about the function of the CTD comes from in vivo genetic analysis. In yeast, progressive deletion of the heptapeptide repeats leads to metabolic deficiencies (Nonet et al. 1987; Allison et al. 1988). A similar genetic approach has shown that the

${ }^{2}$ Corresponding author.
CTD is also essential in Drosophila and cultured mouse cells (Bartolomei et al. 1988; Zehring et al. 1988). Changing the length of the CTD can enhance or suppress the effect of mutations in the yeast transcriptional activator protein GAL4 (Allison and Ingles 1989), and partial deletion of the CTD specifically interferes with recognition of the yeast INO1 upstream activator sequence (UAS) (Nonet and Young 1989; Scafe et al. 1990), suggesting that the CTD may facilitate interaction between RNAP II and factors bound to DNA at remote sites. The CTD may also interact with DNA (Suzuki 1990). This binding has been proposed to play a role in the establishment of transcription complexes, perhaps by allowing displacement of a DNA-bound repressor (Peterson et al. 1991).

The CTD is phosphorylated in vivo at serine and threonine, but not tyrosine, residues (Dahmus 1981; Cadena and Dahmus 1987; Zhang and Corden 1991a). Phosphorylation appears to be cooperative in vivo, generating the highly phosphorylated $\mathrm{II}_{\mathrm{o}}$ form of the large subunit, which displays a substantially retarded mobility in SDSPAGE, relative to the nonphosphorylated $\mathrm{II}_{\mathrm{a}}$ form $(\mathrm{Ca}-$ dena and Dahmus 1987). Although the extent to which the $\mathrm{II}_{\mathrm{o}}$ and $\mathrm{II}_{\mathrm{a}}$ forms are functionally distinct remains uncertain, several lines of evidence suggest that phosphorylation and dephosphorylation of the CTD may be coupled to progression of RNAP II through the transcription cycle (Payne et al. 1989; for review, see Dahmus and Dynan 1992). RNAP II containing the nonphosphory- 
lated $\mathrm{II}_{\mathrm{a}}$ subunit has a selective advantage in forming preinitiation complexes, as evidenced by direct RNAP II-binding experiments (Lu et al. 1991; J.D. Chesnut, J.H. Stephens, and M.E. Dahmus, in prep.) and by the ability of this form to initiate transcription with a shorter lag time in a fractionated system (Kim and Dahmus 1989). In contrast, RNAP II containing the $\mathrm{II}_{\mathrm{o}}$ subunit was found to predominate in elongation complexes, as determined by photo-cross-linking to nascent RNA transcripts (Bartholomew et al. 1986; Cadena and Dahmus 1987; Payne et al. 1989).

A number of CTD kinases have been described/Cisek and Corden 1989; Guilfoyle 1989; Lee and Greenleaf 1989; Payne et al. 1989; Stevens and Maupin 1989; Feaver et al. 1991). One of these has been shown to be involved in CTD phosphorylation in vivo (Lee and Greenleaf 1991), and recently, one has been shown to copurify with a yeast transcription factor (Feaver et al. 1991). Mammalian cells contain a CTD kinase that is of interest because it is associated with preinitiation transcription complexes, providing a plausible mechanism for transition from the $\mathrm{II}_{\mathrm{a}}$ to the $\mathrm{II}_{\mathrm{o}}$ form concomitant with transcriptional initiation (Laybourne and Dahmus 1990; Arias et al. 1991). Significantly, phosphorylation of the CTD by this template-associated kinase occurs when a functional promoter is present in the reaction, and only to a lesser degree with a mutant promoter bearing multiple point changes in the TATA and initiator elements (Arias et al. 1991). Results of a pulse-chase experiment suggest that phosphorylation and transcriptional initiation are closely associated (Arias et al. 1991). These findings suggest that the kinase might be a specific component of the preinitiation complex or, alternatively, that a ubiquitous kinase might respond to conformational changes that accompany promoter binding or initiation of RNA synthesis.

We have developed a simple system based on recombinant substrates to study the activity of the templateassociated kinase. This has allowed us to discriminate between various models that have been proposed regarding CTD phosphorylation. The template-associated kinase does not appear to correspond to one of the known general transcription factors nor one of the kinases that phosphorylates CTD sequences in solution. Rather, it closely resembles a previously known kinase that also phosphorylates $\mathrm{T}$ antigen, $\mathrm{p} 53$, and Sp1. CTD phosphorylation does not require the presence of transcription factors but is strongly enhanced by targeting the CTDcontaining protein to DNA.

\section{Results}

Expression and in vitro phosphorylation of a CTD fusion protein

Previously, we developed an immobilized template transcription system to study the RNAP II transcription reaction (Arias and Dynan 1989). In this system a short promoter-containing DNA fragment, attached at its up- stream end to an agarose bead support matrix, is incubated with nuclear extract to form preinitiation complexes. The complexes are washed to remove unbound proteins. The bound RNAP II initiates transcription in situ upon addition of nucleoside triphosphates. Use of this system results in a 300 -fold purification of transcriptional activity, relative to unfractionated extract. Interestingly, a protein kinase remains tightly associated with the washed preinitiation complexes and phosphorylates the CTD of endogenous RNAP II in a reaction that is closely associated with transcriptional initiation (Arias et al. 1991).

To better understand the underlying mechanism by which the CTD is recognized and phosphorylated in this system, we challenged the system using a recombinant fusion protein containing the murine CTD sequence. This fusion protein, GCTD, which contained a glutathione $S$-transferase (GST) domain joined to the CTD exon, was expressed in Escherichia coli, and affinity purified. When the GCTD protein was added to an immobilized template transcription reaction, transcription was inhibited (Fig. 1A). When the GST control protein lacking the CTD was used, transcription was inhibited only slightly (Fig. 1A, lane h). These results, which are similar to those obtained by Thompson et al. (1989) with conjugated CTD peptide, provide evidence that the GCTD fusion protein was biochemically functional.

To test whether the GCTD protein associated with purified transcription complexes was a substrate for phosphorylation, complexes were assembled in the presence of GCTD as before. The complexes were washed, incubated with nucleoside triphosphates, including $\left[\gamma^{-32} \mathrm{P}\right] \mathrm{ATP}$, and proteins were immunoprecipitated with CTD-specific 8WG16 antibody (Thompson et al. 1989). Two forms of radiolabeled GCTD were detected (Fig. 1B, lane b). The lower mobility $\mathrm{CTD}_{\mathrm{o}}$ form was apparently phosphorylated at multiple sites, and the higher mobility $\mathrm{CTD}_{a}$, which comigrated with the input protein, was apparently phosphorylated at only one or a few sites. The conversion to the mobility-shifted $\mathrm{CTD}_{\mathrm{o}}$ form is similar to the behavior of the native large subunit of RNAP II and other fusion protein substrates in phosphorylation assays (Lee and Greenleaf 1989; Payne et al. 1989). Studies with a model substrate suggest that the addition of approximately seven phosphate groups is required to produce the shift to the $\mathrm{CTD}_{\mathrm{o}}$ form (Zhang and Corden 1991b). Much less radiolabeling was detected when GCTD protein was added subsequent to complex formation (Fig. 1B, lane d), as expected, because there was little inhibition of transcription under these conditions /data not shown). It is interesting that in these experiments the GCTD substrate remained associated with the immobilized template after multiple washes with $250 \mathrm{~mm}$ $\mathrm{KCl}$. This binding appears to be mediated by proteins in the nuclear extract, as we show later that the purified GCTD protein does not bind efficiently to purified DNA (Fig. 3, below).

In addition to the GCTD protein, an endogenous substrate was immunoprecipitated that apparently corresponds to the radiolabeled CTD-containing large subunit 
Figure 1. Behavior of GCTD fusion protein in transcription and phosphorylation assays. (A) Transcription assays: AdMLP DNA beads were incubated with HeLa cell nuclear extract alone (lane $b$ ), with GCTD or GST proteins (see text) in amounts ( $\mu \mathrm{g}$ ) as indicated (lanes $c-h$ ), or with $1 \mu \mathrm{g} / \mathrm{ml}$ $\alpha$-amanitin (lane i) for $1 \mathrm{hr}$ at $30^{\circ} \mathrm{C}$. Transcription was initiated and allowed to proceed for one round as described in Materials and methods. Radiolabeled RNA products were analyzed by $5 \%$ urea-PAGE and visualized by autoradiography. The arrow indicates the 188-nucleotide runoff transcript. HpaII-digested pBR322 molecular mass markers are shown in lane $a .(B)$ Phosphorylation assays: AdMLP DNA beads were incubated with HeLa cell nuclear extract alone (lanes $a, d, e$ ), with $3 \mu \mathrm{g}$ of GCTD protein (lane $b$ ), or with $3 \mu \mathrm{g}$ of GST protein (lane c) for $60 \mathrm{~min}$ at $30^{\circ} \mathrm{C}$. Complexes were washed twice with TX buffer containing $0.25 \mathrm{M} \mathrm{KCl}$ and once with TX buffer containing $0.05 \mathrm{M} \mathrm{KCl}$. Some reactions received an additional $3 \mu \mathrm{g}$ of GCTD protein (lane $d$ ) or GST protein (lane $e$ ), and DNA beads from all of the reactions were washed twice more with TX buffer containing $0.05 \mathrm{M} \mathrm{KCl}$. Phosphorylation was allowed to occur in the presence of $\left[\gamma^{32} \mathrm{P}\right] \mathrm{ATP}$ for $5 \mathrm{~min}$, complexes were washed once in TX buffer containing $0.05 \mathrm{M} \mathrm{KCl}$, and reactions were further incubated, terminated, and immunoprecipitated as described in Materials and methods. Radiolabeled products were analyzed by SDS-PAGE and visualized by autoradiography. Arrows indicate the positions of radiolabeled $\mathrm{GCTD}_{\mathrm{a}}, \mathrm{GCTD}_{\mathrm{o}}$, and RNA polymerase II large subunit. Molecular mass markers are indicated in $\mathrm{kD} .(C)$ Phosphorylation assays using wild-type and mutant templates: AdMLP (lanes $a-c$ ) or mutant AdMLP DNA beads (lanes $d-f$ ) were incubated with HeLa nuclear extract alone (lanes $a, d$ ), with $3 \mu \mathrm{g}$ of GCTD protein (lanes $b, e$ ), or with GST protein (lanes $c, f$ ) for 60 $\min$ at $30^{\circ} \mathrm{C}$. Complexes were washed twice with TX buffer containing $0.25 \mathrm{M} \mathrm{KCl}$ and once with TX buffer containing $0.05 \mathrm{M} \mathrm{KCl}$. Phosphorylation reactions were performed and analyzed as in $B$.

of endogenous RNAP II. Radiolabeling of this endogenous substrate was reduced significantly when GCTD fusion protein was included in the preincubation reaction, whereas control GST protein had little effect (Fig. $1 \mathrm{~B}$, lanes $\mathrm{a}-\mathrm{c})$. This suggests that the GCTD protein acts as a competitive inhibitor of the phosphorylation reaction. This competition, together with the characteristic $\mathrm{CTD}_{\mathrm{a}}$ to CTD mobility shift, suggests that the sites of labeling are in the CTD portion of the molecule. This was confirmed directly in later experiments (see Fig. 4, below).

We have shown previously that radiolabeling of the CTD of endogenous RNAP II is dependent on a functional promoter (Arias et al. 1991). This does not simply reflect the lack of RNAP II substrate bound to mutant DNA beads, as the promoter dependence was also seen in a control experiment where exogenous RNAP II was added to the washed beads during the phosphorylation phase of the reaction (Arias et al. 1991). We wanted to see whether the same promoter dependency was seen with the GCTD fusion protein. It was not. A similar amount of GCTD labeling was seen with wild-type DNA and with a mutant promoter bearing multiple changes in the TATA and initiator elements (Fig. 1C, cf. lanes b and e). In the same experiment, labeling of endogenous substrate was strongly promoter dependent, in agreement with previous findings (Fig. 1C, cf. lanes a and d).

One way to reconcile the different effect of promoter sequences on phosphorylation of the endogenous RNAP II and the GCTD protein is to impute two properties to the kinase: (1) that it binds equally well to wild-type and mutant DNA beads; (2) that it acts only on DNA-bound 
substrates. In this interpretation, promoter sequences are required for RNAP II phosphorylation because they bring RNAP II to the DNA. Binding of the GCTD to the DNA beads is evidently nonspecific, perhaps depending on the high concentration of nuclear extract proteins and GCTD in the reaction, and promoter sequences therefore have no effect on phosphorylation. If this interpretation is correct, the GCTD protein should be made a more efficient substrate by incorporating a site-specific DNAbinding domain, thus targeting the protein to DNA.

\section{Phosphorylation of CTD-GAL4 fusions}

To test the idea that targeting of the CTD to DNA was a key determinant of its activity as a phosphorylation substrate, we constructed a new CTD fusion protein that included the amino acid 1-147 DNA-binding domain of the yeast GAL4 protein. DNA encoding this domain was inserted in-frame between the GST and CTD sequences of pGCTD to create the GC147 construct, as diagramed in Figure 2. The same GAL4 fragment was fused to the GST gene without the CTD, to make the control construct G147. Initially, affinity-purified preparations of GC147 protein were heavily contaminated with smaller polypeptides, probably resulting from degradation or incomplete translation (data not shown). Therefore, GC147 and control proteins used in further experiments were subjected to additional chromatography on a Sephacryl S-300 gel filtration column to give the more purified protein preparations shown in Figure 2. The fusion proteins migrated on SDS-PAGE gels with anomalously low mobilities, as expected from previous reports (Cadena and Dahmus 1987; Zhang and Corden 1991a). For reasons that are not clear, an apparently stoichiometric amount of contaminating GST, seen at the bottom of the gel, reproducibly cochromatographed with the GC147 and G147 proteins. This contaminant is not phosphorylated and should not affect the experiments.

The fusion proteins were tested in an electrophoretic mobility-shift assay for the ability to bind to an oligonucleotide containing a single copy of a 17-nucleotide consensus GAL4-binding site (Fig. 3; Giniger et al. 1985). Both the G147 and GC147 proteins formed complexes with the DNA (lanes c,g). As expected, protein-DNA complexes formed with GC147 had a reduced mobility relative to those formed with G147. DNA binding by GC147 was competed by unlabeled oligonucleotide containing the GAL4 UAS recognition site (lanes $\mathrm{h}-1$ ) but was competed only slightly by an unrelated oligonucleotide (lanes $\mathrm{m}-\mathrm{q}$ ). To show that the DNA-protein complexes formed with GCl47 contained the CTD, complexes were transferred to nitrocellulose and probed with 8WG16 monoclonal antibody (data not shown). The appearance of an immunoreactive band ruled out the possibility that binding might be attributable to incompletely translated or degraded contaminants. Although it has been shown by others that the CTD or CTD peptides bind DNA (Suzuki 1990; Peterson et al. 1991), we did not detect binding of the GCTD protein, which lacks the

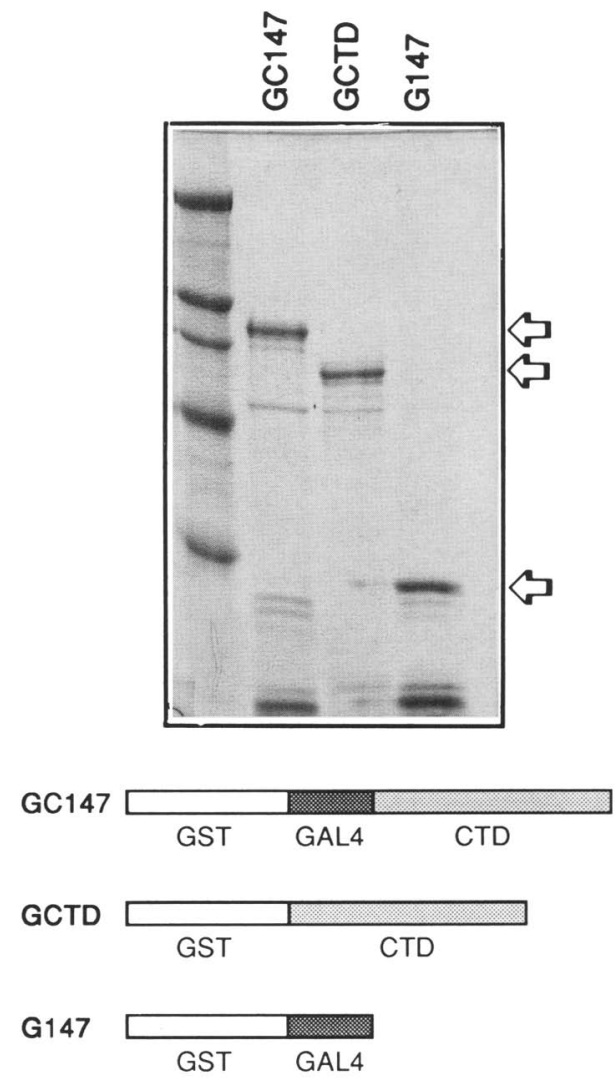

Figure 2. SDS-PAGE analysis of purified fusion proteins. Proteins were expressed and purified as described in Materials and methods. Fifteen microliters of each protein fraction was analyzed by SDS-PAGE using a $7 \%$ running gel and visualized by staining with Coomassie blue dye. The arrows indicate the fulllength fusion proteins. The left lane contains the marker proteins myosin (205 kD), $\beta$-galactosidase ( $116 \mathrm{kD})$, phosphorylase b $(97 \mathrm{kD}$ ), serum albumin (66 kDA), and ovalbumin (45 kD). Diagramed below the gel are the structures of the fusion proteins. The GST protein sequence is represented by the open box, the GAL4 (1-147) DNA-binding domain by the darkly stippled box, and the murine CTD by the lightly stippled box.

GAL4 DNA-binding domain, to the oligonucleotide probe under our standard reaction conditions (Fig. 3, lanes $\mathrm{d}-\mathrm{f}$ ). A small amount of binding was detected with the GCTD protein using a longer DNA probe and a very low ionic strength buffer (M. Galman and W.S. Dynan, unpubl.).

To test purified GC147 fusion protein as a substrate for phosphorylation, preinitiation complexes were formed using HeLa cell nuclear extracts and immobilized template in the presence or absence of GC147. The template used in this experiment was AdUAS, an AdMLP derivative containing the consensus GAL4 recognition sequence. As expected, the GC147 protein was phosphorylated, and its mobility was shifted to the $\mathrm{CTD}_{\mathrm{o}}$ position (Fig. 4A, lane a).

It was of interest to know whether the phosphorylation reaction could be reconstituted in a solution phase assay using kinase eluted from the DNA beads. Com- 


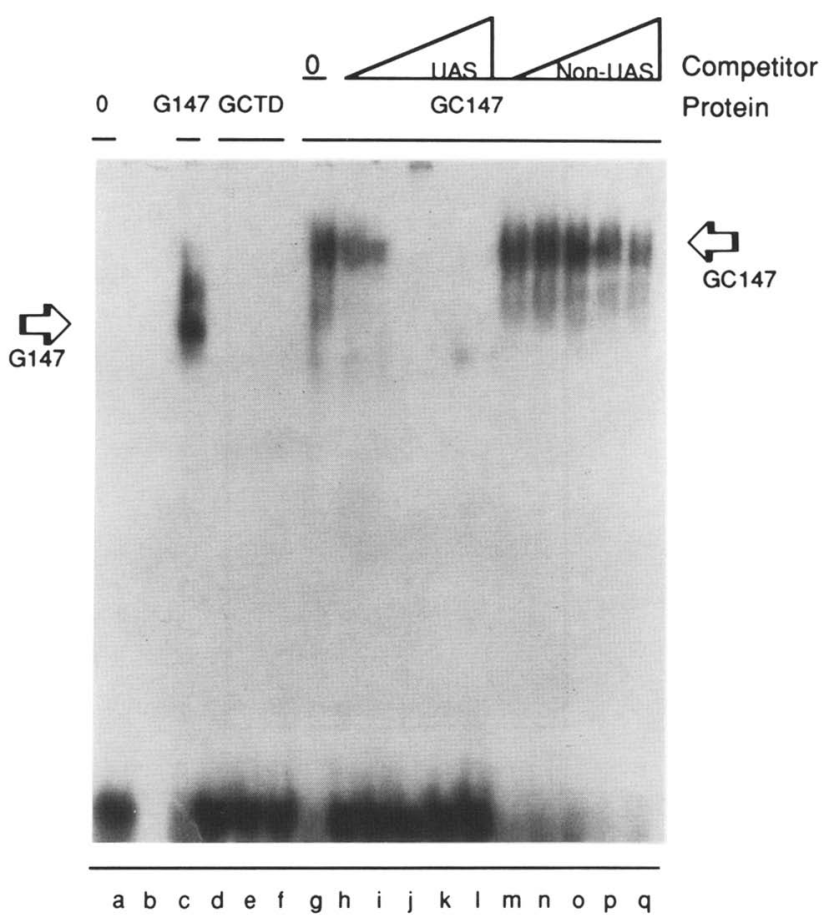

Figure 3. Sequence-specific DNA binding by the G147, GCTD, and GC147 fusion proteins. Radiolabeled probe consisted of an end-labeled, double-stranded oligonucleotide containing a consensus UAS recognized by GAL4. Binding reactions contained $200 \mathrm{pg}$ of probe with no protein (lane $a$ ), $50 \mathrm{ng}$ of G147 protein (lane c), 50, 100, or $200 \mathrm{ng}$ of GCTD protein (lanes $d-f$, respectively), or $50 \mathrm{ng}$ of GC147 protein (lanes $g-q$ ). Some reactions contained nonradiolabeled GAL4 probe as competitor $[20,40,100,200,400 \mathrm{ng}$ (lanes $h-1$, respectively)] or a nonradiolabeled oligonucleotide lacking the GAL4-binding site $[20,40,100,200,400 \mathrm{ng}$ (lanes $m-q$, respectively)]. Reactions were incubated for $15 \mathrm{~min}$ at room temperature and analyzed on a native $5 \%$ polyacrylamide gel. The arrows indicate the mobility-shifted complexes formed by the G147 and GC147 proteins.

plexes were prepared and washed as usual, and incubated in $1 \mathrm{~m} \mathrm{KCl}$. Under these conditions, most proteins are expected to be released, whereas the DNA, which is attached by a streptavidin-biotin linkage, remains associated with the beads. An activity capable of phosphorylating GC147 was detected in the material eluted by $1 \mathrm{M}$ $\mathrm{KCl}$ (Fig. 4A, lane c). The ability of the eluant to catalyze phosphorylation was strongly dependent on the addition of exogenous DNA during the phosphorylation phase of the reaction (cf. lanes $\mathrm{c}$ and d). Binding of kinase to the beads was DNA dependent, as no binding was observed using streptavidin-agarose beads without DNA /data not shown).

To verify that the phosphorylation of the GC147 protein by the DNA bead-eluted kinase was limited to the CTD portion of the protein, the control proteins G147 and GST, which lack the CTD, were tested in parallel kinase reactions with the GC147 protein. No labeling was detected in the proteins lacking the CTD (Fig. 4B, cf. lane $\mathrm{c}$ with lanes $\mathrm{a}$ and $\mathrm{b}$ ). In these reactions, the protein kinase eluted from the DNA beads was sufficiently specific that GC147 phosphorylation could be detected directly, without immunoprecipitation. This method of direct analysis was used in all further experiments.

To confirm further that the CTD was the only site of phosphorylation in these experiments, radiolabeled samples were treated with $\mathrm{CNBr}$. This reagent cleaves at methionine residues, which occur only in the portion of the protein outside the CTD, and thus releases the CTD as an intact polypeptide (Cadena and Dahmus 1987). Incubation of the phosphorylated GC147 protein with $\mathrm{CNBr}$ released two phosphoproteins with electrophoretic mobilities corresponding to the expected $C T D_{a}$ and $\mathrm{CTD}_{\mathrm{o}}$ forms (Fig. 4C, lane b). No other phosphoproteins were detected.

\section{Characteristics of the GC147 phosphorylation reaction}

The time course of CTD phosphorylation was measured, using GCl47 substrate and DNA bead-eluted kinase. Results are shown in Figure 5. Even at short reaction times, there was substantial label in the $\mathrm{CTD}_{\mathrm{o}}$ position and relatively little labeling of species intermediate between the $\mathrm{CTD}_{\mathrm{o}}$ and $\mathrm{CTD}_{\mathrm{a}}$ (Fig. 5A). Thus, under these conditions the transition between the radiolabeled $\mathrm{CTD}_{\mathrm{a}}$ and $\mathrm{CTD}_{\mathrm{o}}$ forms appears to be cooperative. Quantitative PhosphorImager analysis of the experiment is shown in Figure 5B. Interestingly, the appearance of label at the $\mathrm{CTD}_{\mathrm{a}}$ position occurs with no perceptible lag and approaches a plateau value within $10 \mathrm{~min}$, whereas the appearance of label at the CTD o position occurs with a distinct lag and does not plateau until later, a kinetic pattern that is consistent with a precursor-product relationship between the phosphorylated $\mathrm{CTD}_{\mathrm{a}}$ and $\mathrm{CTD}_{\mathrm{o}}$ forms. It has been suggested, as discussed in the introductory section, that phosphorylation of the CTD provides a structural trigger for some subsequent event in the transcription cycle, possibly the initiation of RNA synthesis or release of RNAP II from the promoter. The finding that phosphorylation is cooperative is in agreement with the requirements of this model, where conversion to the $\mathrm{CTD}_{\mathrm{o}}$ form provides an all-or-none signal to some other component of the transcriptional apparatus. It is interesting that the present results differ from those obtained with a CDC2-containing CTD kinase, where the reaction appeared to be distributive, with prominent intermediates detected at short reaction times (Zhang and Corden 1991b).

To examine whether particular DNA sequences were required to activate phosphorylation of the $\mathrm{GCl} 147 \mathrm{fu}-$ sion protein, several DNA fragments were tested as cofactors in the reaction (Fig. 6A). The two fragments that were most effective each contained a GAL4 consensus recognition site (AdUAS and UAS). About threefold more activity was observed with these fragments than with a vector fragment containing no insert (pUC). Presumably, this difference is attributable to DNA binding mediated by the GAL4 (1-147) domain. The residual ac- 
A

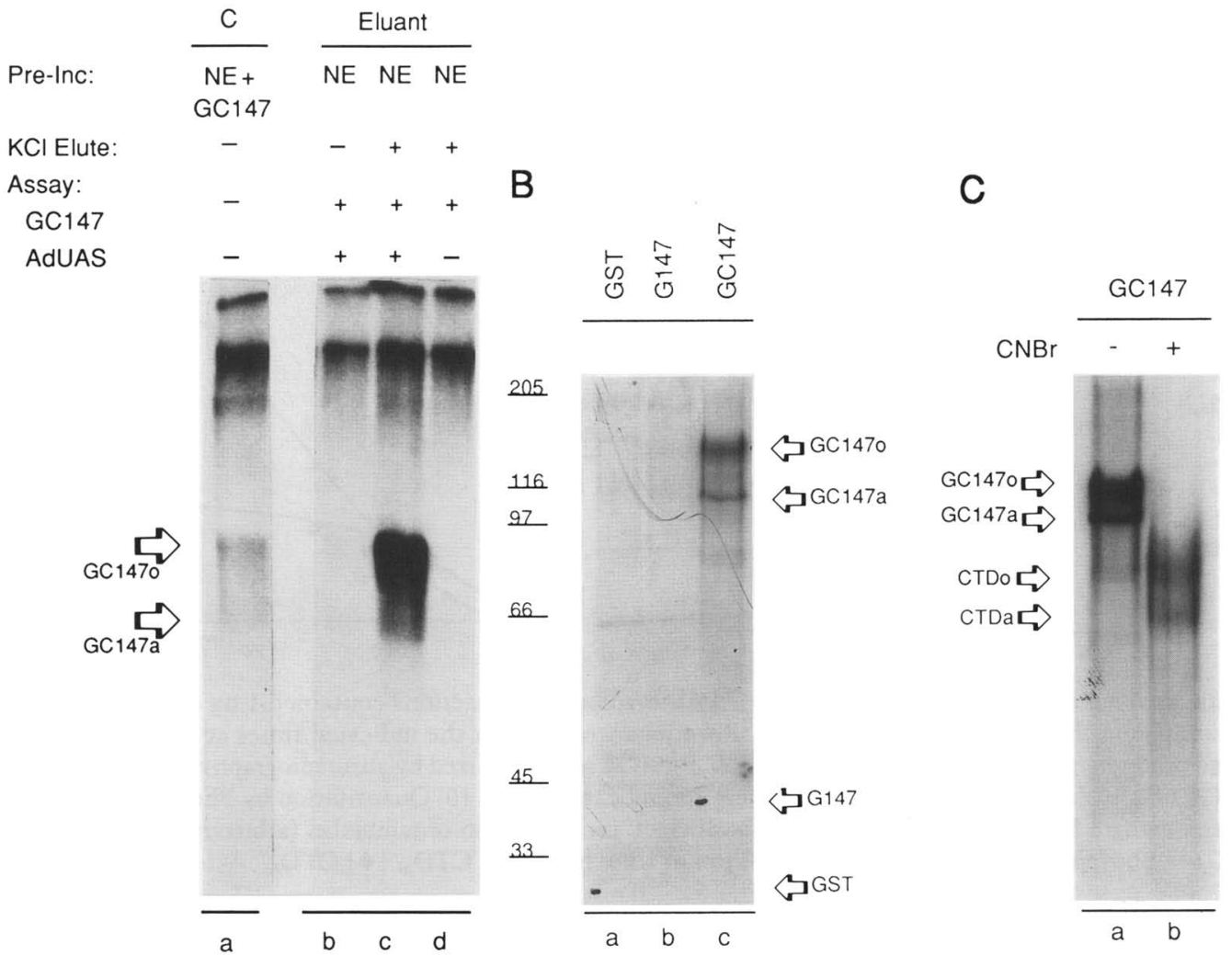

Figure 4. Characterization of CTD kinase eluted from AdUAS DNA beads. (A) Dependence of reaction on kinase and DNA. AdUAS DNA beads $[25 \mu \mathrm{l}$ of a $1: 1$ (vol/vol) slurry] were incubated with $25 \mu \mathrm{l}$ of HeLa nuclear extract in the absence (lanes $b-d$ ) or presence (lane a) of $100 \mathrm{ng}$ of $\mathrm{GC} 147$ protein for $1 \mathrm{hr}$ at $30^{\circ} \mathrm{C}$. Complexes were washed three times with TX buffer containing $0.25 \mathrm{M} \mathrm{KCl}$ and twice with TX buffer containing $0.05 \mathrm{M} \mathrm{KCl}$. DNA beads that had been incubated with GC147 (lane $a$ ) were assayed directly for CTD kinase activity as described below. The other samples were adjusted to $1 \mathrm{M} \mathrm{KCl}$ and incubated for 5 min at $30^{\circ} \mathrm{C}(1$ anes $c, d)$ or treated identically without the $1 \mathrm{M} \mathrm{KCl}$ elution (lane $b$ ). The eluant was separated from the DNA beads by centrifugation and dialyzed against TX buffer containing $0.05 \mathrm{M} \mathrm{KCl}$. Phosphorylation reactions were performed in the presence or absence of $100 \mathrm{ng}$ of GC147 protein and $150 \mathrm{ng}$ of AdUAS DNA fragment as indicated in TX buffer containing $0.05 \mathrm{M} \mathrm{KCl}$. Reactions containing $100 \mathrm{mM}$ CTP, GTP, UTP and $\left[\gamma^{-32} \mathrm{P}\right] \mathrm{ATP}$ (4 Ci/mmole) were incubated $30 \mathrm{~min}$ at $30^{\circ} \mathrm{C}$. Radiolabeled products were immunoprecipitated with $8 \mathrm{WG} 16$ antibodies, analyzed by $7 \%$ SDS-PAGE, and visualized by autoradiography. $(B)$ Phosphorylation requires the CTD. Reactions contained 1 ng of AdUAS DNA fragment $100 \mathrm{ng}$ of GST, G147, or GC147 protein as indicated, and the DNA bead-eluted kinase. Reactions were incubated for $30 \mathrm{~min}$ as described in Materials and methods, and products were analyzed directly without immunoprecipitation by $8 \%$ SDS-PAGE and visualized by autoradiography. Arrows indicate the positions of GC147 $a$ and GC147。 isoforms and expected positions of G147 and GST control proteins. Molecular mass markers are indicated in kD. $\{C\rangle \mathrm{CNBr}$ cleavage of phosphorylated GC147 protein. Reaction contained $1 \mathrm{ng}$ of AdUAS DNA fragment, $100 \mathrm{ng}$ of GC147 protein, and the DNA bead-eluted kinase and was run as in $B$. Phosphorylated products were incubated for $3 \mathrm{hr}$ at $25^{\circ} \mathrm{C}$ in $50 \mathrm{~mm} \mathrm{HCl}$ and $0.2 \%$ SDS (lane $a$ ) or in the same buffer with $50 \mathrm{mM} \mathrm{CNBr}$ (lane $b$ ). Reactions were neutralized with $1 \mathrm{~N} \mathrm{NaOH}$, and products were analyzed directly by $10 \%$ SDS-PAGE and visualized by autoradiography. Arrows indicate the positions of $\mathrm{GCl}_{147}$ and $\mathrm{GCl}_{\mathrm{a}}$ o isoforms and $\mathrm{CNBr}_{\mathrm{c}}$ cleaved $\mathrm{CTD}_{\mathrm{a}}$ and $\mathrm{CTD}_{\mathrm{o}}$ products. Molecular mass markers are indicated in $\mathrm{kD}$.

tivity with the vector fragment is probably attributable to nonspecific binding by the GAL4 domain under the conditions of protein excess that are used in these reactions. Significantly, when the GAL4 recognition site was present, it made little difference whether the activating fragment contained the adenovirus 2 major late promoter (AdMLP) sequence, suggesting that the phosphorylation reaction does not require any specific interactions with promoter sequences. In the absence of the GAL4 recognition site, a fragment containing the AdMLP sequence ( $\mathrm{Ad}$ ) was more effective than the pUC vector fragment alone. This difference is as yet unexplained; it could reflect an authentic contribution from the promoter or, alternatively, the occurrence of a weak, adventitious GAL4 recognition site somewhere within the AdMLP construct.

Further evidence that targeting of the CTD to DNA is important for phosphorylation is provided by a direct comparison of the GC147 and GCTD proteins in a phosphorylation assay (Fig. 6B). The initial velocity of the reaction is markedly higher with GC147, where the GAL4 DNA-binding domain is present, than with the 
A

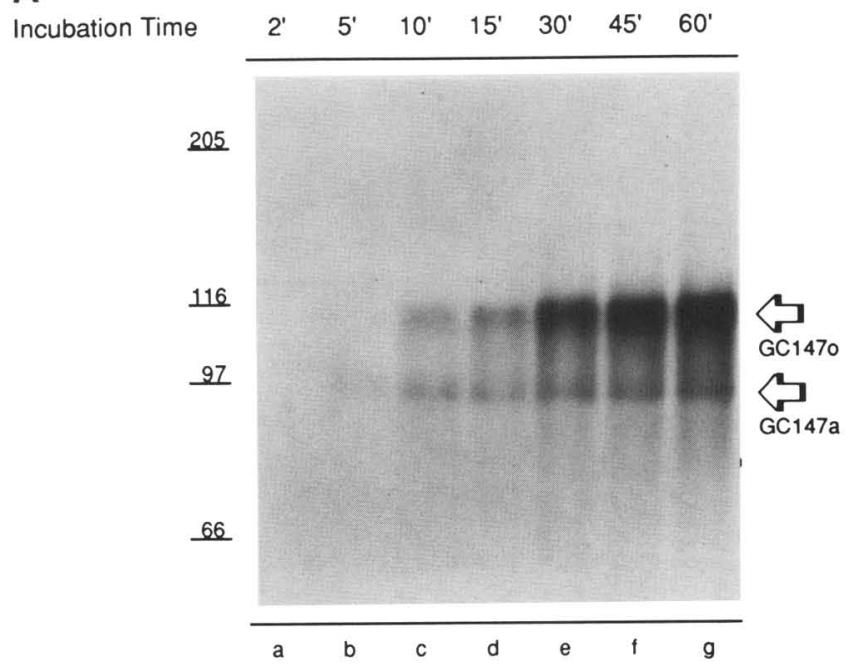

B

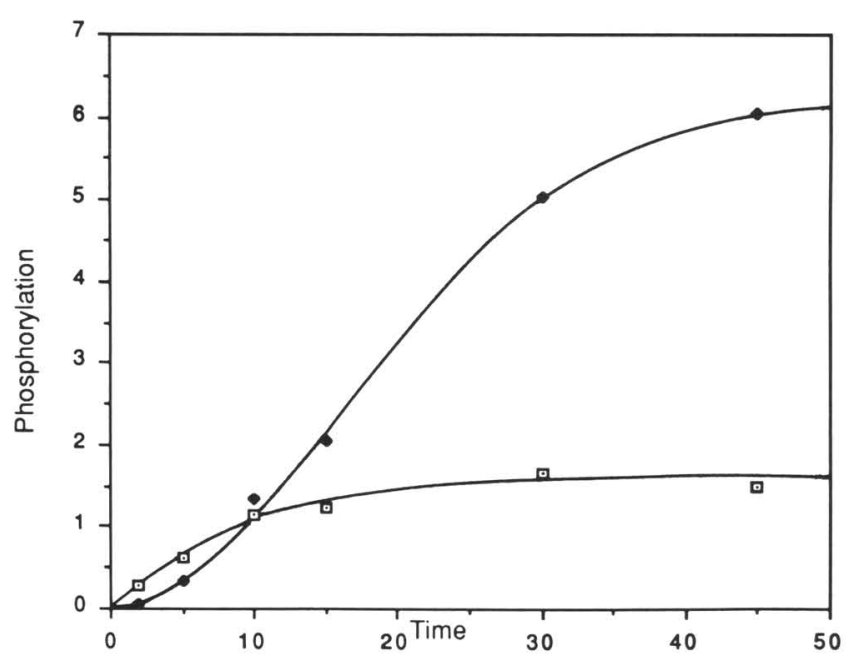

Figure 5. Kinetic analysis of GC147 phosphorylation. (A) Autoradiograph. Reactions contained 1 ng of AdUAS DNA fragment, 100 ng of GC147 protein, and the DNA bead-eluted kinase. Reactions were run for the indicated times at $30^{\circ} \mathrm{C}$ as described in Materials and methods, and products were analyzed directly by $7 \%$ SDS-PAGE and visualized by autoradiography. Arrows indicate the positions of $\mathrm{GCl}_{14}$ and GC147。 isoforms. Molecular mass markers are indicated in $\mathrm{kD}$. (B) Quantitation by PhosphorImager analysis. The gel in $A$ was analyzed using a Molecular Dynamics Phosphorlmager. Incorporation of radiolabel (arbitrary units) into the $\mathrm{II}_{\mathrm{o}}$ and the $\mathrm{II}_{\mathrm{a}}$ forms of the GCl47 phosphoprotein is shown as a function of time $(\mathrm{min})$. (i) $\mathrm{CTD}_{\mathrm{a}}(\downarrow) \mathrm{CTD}_{\mathrm{o}}$.

GCTD control protein, where the DNA-binding domain is absent. Because the reaction responds to both the presence of the GAL4 DNA-binding domain in the protein and the GAL4 recognition site in the DNA, the simplest interpretation is that the binding of the substrate to the DNA provides the signal for phosphorylation. Our results do not rule out the possibility that the GAL4 insert makes some additional contribution to substrate activ- ity, however, perhaps by changing the overall structure of the fusion protein. This idea will be taken up further in the Discussion.

The requirements of the kinase for nucleotide substrates were investigated using the solution-phase assay. The $K_{\mathrm{m}}$ for ATP was $\sim 7 \mu \mathrm{M}$ (data not shown), consistent with the apparent $K_{\mathrm{m}}$ for ATP in the endogenous reaction (Laybourn and Dahmus 1990). Under standard con-
A

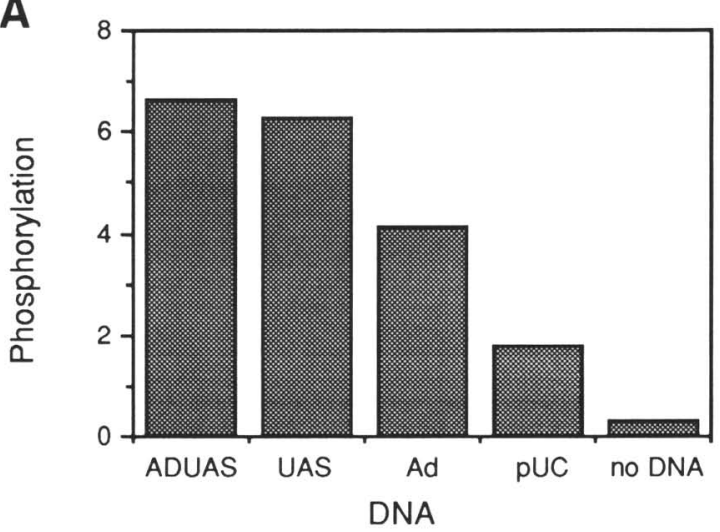

B

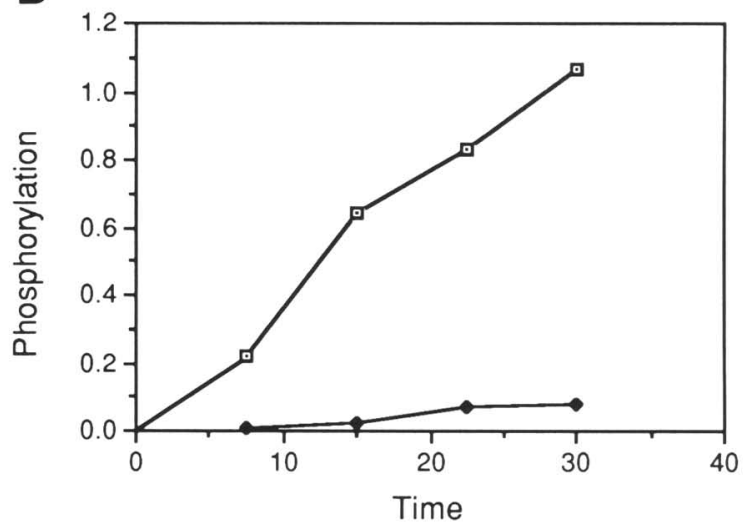

Figure 6. DNA sequence dependence of phosphorylation of GC147 protein and comparison of the GC147 and GCTD substrates. (A) Phosphorylation assays of GC147\% in the presence of different DNA fragments. Reactions contained $1 \mathrm{ng}$ of each of $E c 0 \mathrm{RI}-\mathrm{Bg} \mathrm{II}$ fragments derived from pAdUAS, pUCUAS, pAdMLP, or pUC 19, as indicated; $100 \mathrm{ng}$ of GC147 protein; and the DNA bead-eluted kinase. Reactions were run for $30 \mathrm{~min}$ at $30^{\circ} \mathrm{C}$, and products were analyzed by $8 \%$ SDS-PAGE. The amount of radiolabel incorporated (arbitrary units) into the $\mathrm{II}_{\mathrm{o}}$ form of the phosphoprotein was determined by PhosphorImager analysis. $(B)$ Comparison of GCTD $(\bullet)$ and GC147 $(\cdot)$ substrates. Reactions contained $1 \mathrm{ng}$ of AdUAS DNA fragment, $100 \mathrm{ng}$ of GCTD protein or GC147 protein, and the DNA bead-eluted kinase. Reactions were run for $7.5,15,22.5$, and $30 \mathrm{~min}$ at $30^{\circ} \mathrm{C}$, and the amount of radiolabel incorporated (arbitrary units) into the $\mathrm{II}_{\mathrm{o}}$ form of the phosphoprotein was determined as in $A$. 
ditions, there was an $\sim 10$-fold preference for ATP over GTP (data not shown).

The template-associated CTD kinase resembles a kinase described previously

The experiments presented here show that the templateassociated CTD kinase is strongly dependent on DNA as a cofactor for the reaction. It binds tightly but nonspecifically to DNA and is present in nuclear fractions. It has been shown to have a very strong preference for ATP over GTP and has been shown previously to be resistant to the nucleoside analog DRB (Arias et al. 1991). Only one other kinase with these properties has been reported previously (Walker et al. 1985; Lees-Miller and Anderson 1989; Carter et al. 1990; Lees-Miller et al. 1990). This well-characterized DNA-dependent protein kinase (DNA-PK) phosphorylates hsp90, $\alpha$-casein, phosvitin, and several nuclear proteins, including SV40 T antigen, human Ku antigen, p53, and Spl (Walker et al. 1985; Jackson et al. 1990; Lees-Miller et al. 1990).

To test whether the previously described DNA-PK phosphorylates the CTD, the enzyme was isolated according to the published procedure (Lees-Miller et al. 1990) and tested in a phosphorylation assay with GC147 substrate. Extensive labeling was detected at both $\mathrm{CTD}_{\mathrm{a}}$ and $\mathrm{CTD}_{\mathrm{o}}$ positions (Fig 7A, lane i). The reaction was strongly dependent on DNA (cf. lanes $i$ and j). Very little phosphorylation was seen with the GCTD protein lacking the GAL4 DNA-binding domain (cf. lanes $\mathfrak{j}$ and 1 ). The expected DNA-dependent phosphorylation of an hsp90 control protein was seen (lanes g,h). Parallel reactions were performed using material eluted from immo-

A

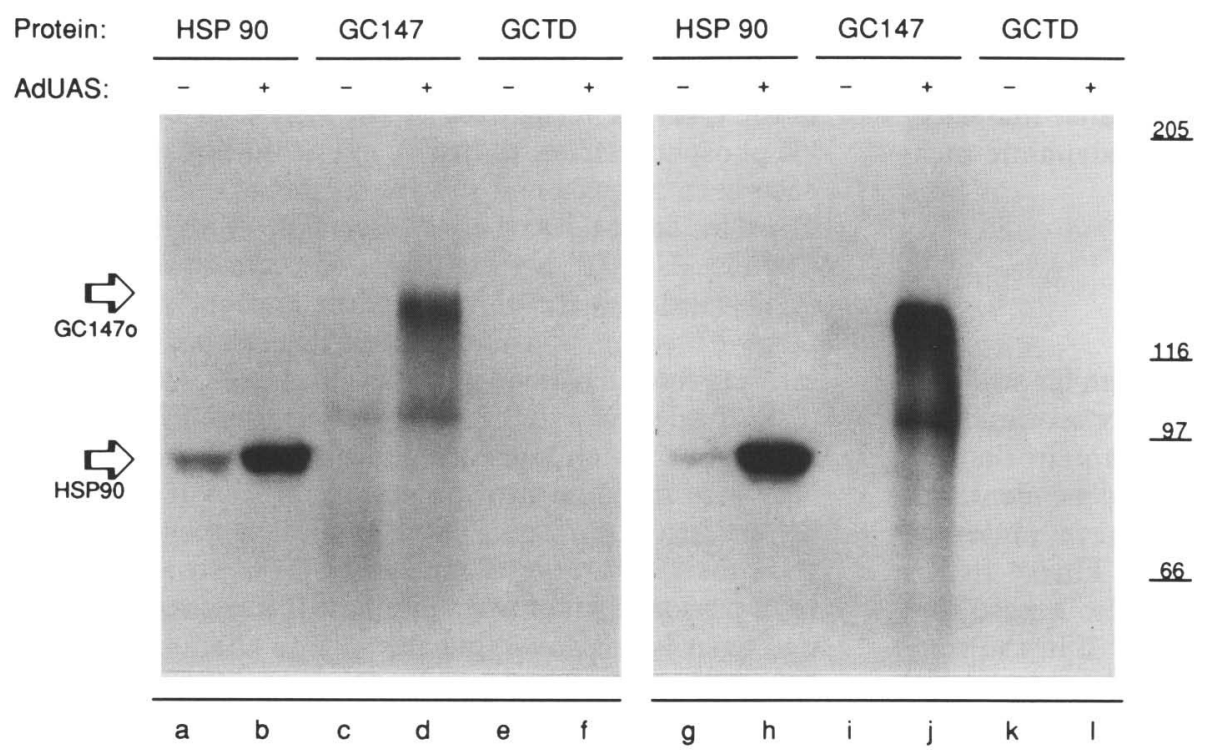

B

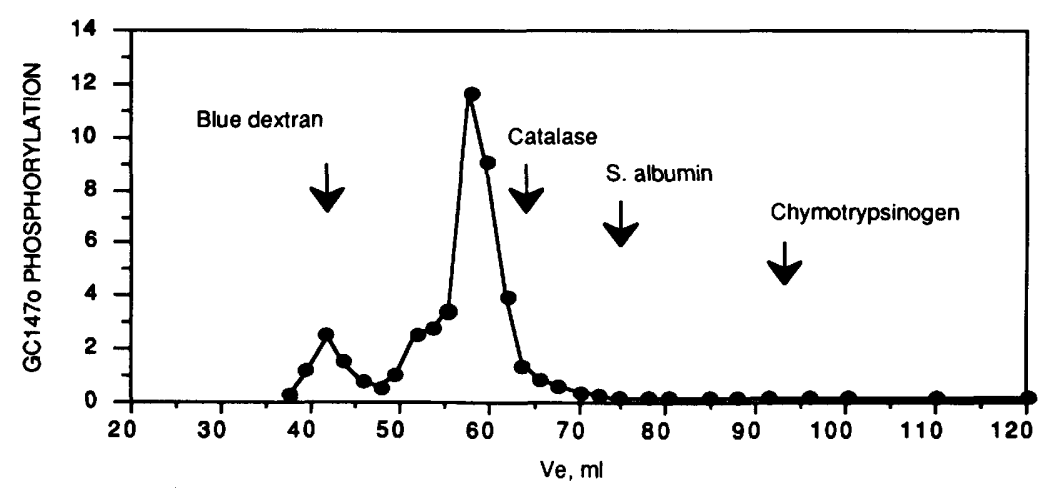

Figure 7. Comparison of DNA bead-eluted protein kinase and isolated DNA-dependent protein kinase. $(A)$ Comparison of kinase reaction products. Phosphorylation reactions were performed as described in Materials and methods using $2 \mu \mathrm{l}$ of DNA bead-eluted kinase (lanes $a-f$ ) or $100 \mathrm{ng}$ of a purified preparation of DNA-PK (lanes $g-1$ ). Reactions contained $1 \mathrm{ng}$ of AdUAS DNA fragment and $250 \mathrm{ng}$ of hsp90 protein, $100 \mathrm{ng}$ of GC147 protein, or $100 \mathrm{ng}$ of GCTD protein, as indicated. Phosphorylation reactions were performed for $30 \mathrm{~min}$ at $30^{\circ} \mathrm{C}$, and products were analyzed by SDS-PAGE and visualized by autoradiography. Lanes $a-f$ were exposed three times as long as lanes g-1. (B) Superdex-200 chromatography of DNA bead-eluted kinase. Material eluted with $1 \mathrm{M} \mathrm{KCl}$ from $200 \mu \mathrm{l}$ of AdMLP DNA beads was fractionated on a Superdex-200 H16/160 column, and kinase activity was measured for the indicated fractions as described in Materials and methods. 
bilized template DNA beads (Fig 7A, lanes a-f). The pattern of radiolabeling was essentially indistinguishable from that seen with isolated DNA-PK.

DNA-PK is distinguished from most other protein kinases by its large size, with a native molecular mass of $\sim 300-350 \mathrm{kD}$, as determined by gel-filtration chromatography (Carter et al. 1990; Lees-Miller et al. 1990). To establish whether our template-associated CTD kinase shared this distinctive property with DNA-PK, material was eluted from DNA beads and subjected to further chromatography on a Superdex-200 gel-filtration column (Fig. 7B). The bulk of the activity eluted in a well-defined peak between the void volume and catalase, consistent with a molecular mass of $\sim 300 \mathrm{kD}$. As expected, this activity was strongly DNA dependent (data not shown). There was a small secondary peak of CTD kinase activity eluting at the void volume. This activity was DNA independent, however, suggesting that it might be attributable to large complexes formed between kinase and contaminating DNA in the preparation. The behavior of our template-associated kinase in gel filtration is consistent with that reported previously for DNA-PK /Carter et al. 1990; Lees-Miller et al. 1990). It differs from the behavior expected for the CDC2-containing CTD kinases, however, which have native molecular masses of 93 and $89 \mathrm{kD}$, as determined from hydrodynamic measurements (Cisek and Corden 1991).

\section{Discussion}

We have developed a model reaction system for studying phosphorylation of the RNAP II carboxy-terminal domain. The system is based on a fusion protein that positions the CTD on a DNA fragment independently of transcription complex formation. We have presented four lines of evidence that the protein kinase in the model reaction system is the same as the kinase that phosphorylates the CTD of native RNAP II in the transcription complex. First, the kinase used in the model reactions was obtained from washed preinitiation complexes. Second, when the kinase in the model reaction phosphorylates its substrate, the substrate undergoes an electrophoretic mobility shift similar to that seen when the native large subunit of RNAP II is phosphorylated. Third, the kinase in the model reaction has the same nucleotide substrate specificity as the kinase that phosphorylates RNAP II in the transcription complex, including a similar $K_{\mathrm{m}}$ for ATP and a preference for ATP over GTP. Finally, the kinase in both reactions prefers a DNA-bound substrate. For the phosphorylation of native RNAP II, this is manifested as a requirement for a promoter sequence in the reaction. For the phosphorylation of the model substrate, this is manifested as a requirement for a DNA-binding domain in the substrate and a preference for DNA containing the cognate-binding site. Taken together, these findings argue strongly that the system we have reconstituted from isolated components provides a faithful model for studying the phosphorylation of the CTD of RNAP II in the transcription reaction.
The properties of the template-associated CTD kinase, particularly the DNA dependence, suggested that it might also be the same as a DNA-dependent protein kinase that has been described previously (Walker et al. 1985; Carter et al. 1990; Lees-Miller et al. 1990). Direct comparison of the isolated DNA-PK with kinase eluted from the DNA beads showed that their activities were indistinguishable with both CTD and hsp90 substrates. Previous work suggests that DNA-PK activity is associated with a $300-$ to $350-\mathrm{kD}$ polypeptide (Carter et al. 1990; Lees-Miller et al. 1990). It is not known whether this polypeptide is sufficient for activity or whether it contains the active site. Thus, although the templateassociated CTD kinase shares the reported properties of DNA-PK, further biochemical analysis will be needed to determine whether it is fully identical to the enzyme that phosphorylates $\mathrm{Sp} 1, \mathrm{~T}$ antigen, and other characteristic substrates. We cannot exclude the possibility that the enzyme exists in several forms, perhaps associated with different regulatory subunits. Because the model reaction is largely independent of promoter sequences, it is unlikely that the kinase corresponds to any specific component of the preinitiation complex.

It will be of interest to determine precisely which sites in the CTD are recognized by the kinase. Sites of DNAPK phosphorylation in hsp90 and SV40 large T antigen have been mapped and shown to consist of Ser-Gln and Thr-Gln dipeptides (Lees-Miller and Anderson 1989; Chen et al. 1991), neither of which occur in the murine CTD (Corden et al. 1985). However, a recently identified DNA-PK serine phosphorylation site in rat c-fos occurs in a peptide that does not contain a Ser-Gln sequence (C.W. Anderson and S.P. Lees-Miller, unpubl.). Information about which sites are phosphorylated in the CTD may give insights into the structural transition that is believed to occur upon phosphorylation (Laybourn and Dahmus 1989). Several models of CTD structure have been proposed, all of which include $\beta$ turns stabilized by hydrogen bonds involving serine side chains (Matsushima et al. 1990; Suzuki 1990). These contacts would be disrupted by serine phosphorylation.

Other kinases capable of phosphorylating the CTD have been described (Guilfoyle 1989; Lee and Greenleaf 1989; Stevens and Maupin 1989). E1 and E2, both of which contain the mouse homolog of the yeast CDC2 protein, have been the kinases characterized most thoroughly (Cisek and Corden 1989, 1991; Zhang and Corden $1991 \mathrm{a}, \mathrm{b})$. These kinases are apparently distinct from the template-associated kinase described here and in our previous study (Arias et al. 1991). The CDC2-containing kinases utilize GTP as a substrate, they are sensitive to the inhibitor DRB and, more significantly, they were identified by assaying for phosphorylation of free CTD peptide or fusion protein in the absence of DNA, a condition under which DNA-PK has little or no activity. The physiological role of the CDC2-containing kinases is presumably different than that of the template-associated kinase; perhaps they are involved in cell cycle-dependent regulation of transcription.

A key feature of our present results is the requirement 
that the CTD substrate be bound to DNA. Because the DNA-PK binds to DNA /Carter et al. 1990; Lees-Miller et al. 1990), binding of the CTD may accelerate the reaction by increasing the local concentration of substrate. Alternatively, or in addition, the actual recognition target for the kinase may be a complex formed directly between the CTD heptapeptide repeats and DNA. Under the conditions used for phosphorylation assays, we did not observe stable binding of the CTD to DNA unless the GAL4 domain was present (Fig. 3). These data do not, however, rule out the existence of a transient interaction between the heptapeptide repeats and DNA. Model CTD peptides have been shown to bind DNA by intercalation (Suzuki 1990), and a full-length yeast CTD fusion protein has been shown to bind DNA nonspecifically under conditions of very low ionic strength (Peterson et al. 1991). It is possible that these interactions, even if weak, may provide a physiologically important signal to the kinase.

Binding of RNAP II to DNA is more complicated than binding of the GCl47 model substrate. Notably, binding of RNAP II to the promoter is dependent on general transcription factors, including TFIIA, TFIIB, TFIID, and TFIIF (Van Dyke et al. 1988; Buratowski et al. 1989; Flores et al. 1991). Phosphorylation of the native CTD is likely to occur in a complex that includes these and perhaps other transcription factors. Our present data argue that contacts between the CTD and general transcription factors are not required for phosphorylation of the model substrate, as the reaction occurs with isolated DNA-PK and in the absence of AdMLP sequences. Whether such contacts are important for phosphorylation of the native CTD remains to be determined.

We have considered the possibility that the presence of the GST or GAL4(1-147) domains of the fusion protein might stimulate phosphorylation within the attached CTD sequence. This is given particular credence by the observation that although the GAL4(1-147) fragment does not contain either of the two observed in vivo GAL4 transcriptional activating domains, it will activate transcription in vitro, evidently through a sequence located between residues 74 and 147 (Lin et al. 1988). It is possible that the CTD interacts with this in vitro-activating domain, and that this, in concert with DNA binding, provides a composite signal to the kinase. We have attempted to test this possibility by constructing a CTD fusion protein containing only GAL4 amino acids $1-74$, which form the core of the DNA-binding domain and do not activate transcription in vitro. This protein was indeed phosphorylated at a lower initial rate /S.R. Peterson and W.S. Dynan, unpubl.). However, it also bound more weakly to its recognition site, and this difference in binding may have been sufficient to explain the reduction in phosphorylation.

The physiological role of CTD phosphorylation is of prime interest. Genetic data suggest that the CTD helps mediate the interaction between the core transcriptional machinery and factors bound at distant sites. It is uncertain whether these effects are direct or indirect. It has been proposed that the CTD might make hydrogen bond contacts with acidic activating regions (Sigler 1988), but one can also imagine that it might displace a repressor (Peterson et al. 1991) or interact with the DNA to promote the formation of loops between the promoter and transcription factors at remote sites. Phosphorylation of the CTD at the time of initiation would serve to break up contacts between the CTD and other proteins, promoting the transition to the elongation complex. It has been suggested that initiation of RNA synthesis or the formation of a stable preinitiation complex might provide a signal to the kinase, triggering initiation. Although this could be true for phosphorylation of the native CTD in the transcription complex, studies with the model system have so far provided no specific support for these ideas but, instead, suggest that DNA binding alone provides a signal triggering phosphorylation.

What is the possible role of a kinase that phosphorylates the DNA-bound CTD at a relatively constant rate, independent of other components of the complex? We suggest that a kinase with this characteristic could function effectively as part of a proofreading mechanism that enhances the fidelity of promoter recognition. When RNAP II binds nonspecifically to DNA, it dissociates rapidly. At an authentic promoter sequence, however, dissociation is slow relative to the rate of CTD phosphorylation. Rather than dissociating, the RNAP II will instead be phosphorylated, undergo a conformational change (Laybourn and Dahmus 1989), and progress irreversibly to the next step of the reaction. At this stage, there is a branch in the pathway, providing an opportunity for the now altered transcription complex to dissociate prior to the formation of the first phosphodiester bond in the nascent RNA. This dissociation is irreversible, as the $\mathrm{II}_{\mathrm{o}}$ form of RNAP II cannot rebind to DNA. One can write a formal kinetic scheme that is identical to that for translational proofreading in E. coli (Thompson 1988). Although the proofreading model has yet to be tested in detail, it is consistent both with our present data and with several previous observations, including the loss of transcriptional activity when preinitiation complexes are incubated with ATP in the absence of initiating nucleotides (Cai and Luse 1987; Conaway and Conaway 1988) and the relationship between CTD phosphorylation and transcription observed using an in vitro pulse-chase labeling protocol (Arias et al. 1991).

\section{Materials and methods}

\section{Expression and purification of CTD fusion proteins}

Expression plasmids were based on pGEX2T (Pharmacia), which contains a gene encoding a $29-\mathrm{kD}$ GST domain with a polylinker at the $3^{\prime}$ end (Smith and Johnson 1988). GST transcription is under the control of the IPTG-inducible tac promoter in a lac $i^{q}$ background. A DNA fragment encoding the CTD was amplified from genomic DNA of a BALB/c mouse cell line by polymerase chain reaction. Primers were designed using the sequence of Ahearn et al. (1987). The sequence of the upstream primer, CTD1, was 5'-TTGTCTGGATCCGTAGGTGGTGCTATGTCTCCC-3'. An introduced BamHI site is underlined, as is the first codon of the natural CTD exon. The sequence of the 
downstream primer, CTD2, was 5'-CCTAACGAATTCTTCGCCCTGTTCGCTCAGTT- $3^{\prime}$. An introduced EcoRI site is underlined, as is the sequence complementary to the natural CTD termination codon. The DNA was subjected to 30 cycles of amplification, gel-purified, and digested with EcoRI and BamHI. The fragment was inserted into pGEX2T, which was digested with $B a m H I$ and EcoRI. Following transformation, bacterial colonies were screened for CTD sequences and for the ability to express fusion protein reactive with a monoclonal antibody (8WG16) specific for the CTD (Thompson et al. 1989). The structure of the resulting cloned plasmid, pGCTD, was confirmed by restriction analysis and partial DNA sequencing.

To make the GC147 construct, a DNA fragment encoding the first 147 amino acids of the yeast GAL4 protein was amplified from a GAL4-encoding plasmid. Primers were designed using data of Laughon and Gesteland (1984). The GAL4-1 primer sequence was 5'-CAAGCCTCCGGATCCATGAAGCTACTGTCT-3', and the GAL4-2 primer sequence was 5'-TGCCGA GGATCCCGATACAGTCAACTGTCT- $3^{\prime}$. Introduced BamHI sites are underlined. The amplified fragment was digested with BamHI and inserted into pGCTD, which was digested with BamHI. The resulting plasmid, pGC147, encoded an in-frame insertion of amino acids 1-147 of GAL4 between the GST and CTD domains of pGCTD. The pGl47 plasmid was created by cloning the same GAL4 fragment into the pGEX2T vector at the BamHI site. The resulting plasmid is analogous to pGC147 but lacks the CTD.

Large-scale purification of these proteins was achieved by inducing exponentially growing $E$. coli cultures $\mid O D_{600}=0.61$ with $0.5 \mathrm{mM}$ IPTG and incubating at $30^{\circ} \mathrm{C}$ for $7-9 \mathrm{hr}$. Cells were harvested by centrifugation and resuspended in $1 / 100$ culture volume of TZ buffer [ $50 \mathrm{mM}$ Tris- $\mathrm{HCl}$ (pH 7.9), $12.5 \mathrm{mM} \mathrm{MgCl}_{2}, 0.5$ mM EDTA, $100 \mathrm{mM} \mathrm{KCl}, 20 \%$ glycerol, $1 \mathrm{~mm} \beta$-mercaptoethanol, $10 \mu \mathrm{M} \mathrm{ZnCl}_{2}$ ], and $1 \mu \mathrm{g} / \mathrm{ml}$ of each of the protease inhibitors phenylmethylsulfonyl fluoride (PMSF), soybean trypsin inhibitor, and leupeptin, and $1 \%$ Triton X-100 (Sigma). Cells were disrupted in a French press, the lysate was cleared of debris by centrifugation at $10,000 \mathrm{~g}$ for $10 \mathrm{~min}$, and the supernatant was collected. The pellet was re-extracted with $1 / 25$ culture volume of $T Z$, the mixture was centrifuged as before, and the supernatant was collected. The supernatants were pooled and incubated for $30 \mathrm{~min}$ at room temperature with S-linked glutathione-agarose (Sigma) at a ratio of $1.25 \mathrm{ml}$ of resin per liter of culture volume in $40-\mathrm{ml}$ batches. The mixture was centrifuged, and the resin was washed once with $20 \mathrm{vol}$ of buffer containing $50 \mathrm{~mm}$ Tris- $\mathrm{HCl}(\mathrm{pH}$ 7.9), $1 \mathrm{M} \mathrm{NaCl}, 1 \mathrm{~mm} \beta$-mercaptoethanol, and protease inhibitors as above and washed once more with $20 \mathrm{vol}$ of PBS containing $1 \%$ Triton X-100, $1 \mathrm{~mm} \beta$-mercaptoethanol, and protease inhibitors. GST fusion proteins were eluted with $\mathrm{TZ}$ buffer containing $15 \mathrm{~mm}$ reduced glutathione (Sigma) and dialyzed against TZ buffer. Unless otherwise noted in the text, proteins were purified further using a $60-\mathrm{ml}$ Sephacryl S-300 column (Pharmacia) equilibrated with TZ buffer. Fractions were analyzed by SDS-PAGE with Coomassie blue staining, and fractions containing full-length fusion protein were pooled, flash frozen in liquid $\mathrm{N}_{2}$, and stored in aliquots at $-70^{\circ} \mathrm{C}$. Quantitation of the fusion proteins was performed by comparing Coomassie blue dye binding of the full-length proteins to known standards, with the assumption that the CTD portion of the protein did not bind dye (Zhang and Corden 1991a).

The AdMLP DNA /referred to in the text as the AdMLP fragment) consisted of a 258-bp EcoRI-BglI DNA fragment derived from pDNAdML (Conaway and Conaway 1988). The mutant AdMLP was described previously (Arias et al. 1991). The pAdUAS and pUCUAS plasmids were created by inserting a consensus GAL4 17-mer binding site consisting of an oligo- nucleotide 5'-CCGCGGAAGACTCTCCTCCGGTAC-3' and its complement 5'-CGGAGGAGAGTCTTCCGCGGGTAC-3' (Giniger et al. 1985) into the KpnI site of pDNAdML or pUC19, respectively.

\section{Immobilized template transcription and phosphorylation assays}

Nuclear extracts were prepared from HeLa cells as described previously (Arias and Dynan 1989). For transcription assays, preinitiation complexes were formed by incubating $30 \mu \mathrm{l}$ of AdMLP DNA beads $[1: 1(\mathrm{vol} / \mathrm{vol})$ in water, $750 \mathrm{ng}$ of DNA per reaction] with $30 \mu \mathrm{l}$ of $\mathrm{HeLa}$ cell nuclear extract for $60 \mathrm{~min}$ at $30^{\circ} \mathrm{C}$. Some reactions also contained GCTD or GST proteins as indicated in the figure legends. Transcription was initiated from these complexes by incubating for $10 \mathrm{~min}$ at $30^{\circ} \mathrm{C}$ with $250 \mu \mathrm{M}$ AMP-PNP, $250 \mu \mathrm{M}$ UTP, $12.5 \mu \mathrm{M}$ CTP, and $12.5 \mu \mathrm{M}$ ATP. Sarkosyl was added to $0.5 \%$, and the complexes were washed three times with $1 \mathrm{ml}$ of ice-cold TX buffer $[25 \mathrm{~mm}$ Tris- $\mathrm{HCl}$ ( $\mathrm{pH} 7.9)$, $6.25 \mathrm{mM} \mathrm{MgCl}_{2}, 0.25 \mathrm{~mm}$ EDTA, $1 \mathrm{~mm}$ dithiothreitol (DTT), $10 \%$ glycerol] containing $0.05 \mathrm{M} \mathrm{KCl}$. Elongation nucleotides |final concentration, $250 \mu \mathrm{M}$ GTP, $250 \mu \mathrm{M}$ UTP, $250 \mu \mathrm{M}$ ATP, $12.5 \mu \mathrm{M} \alpha{ }^{32} \mathrm{P}$-labeled CTP $(8 \mathrm{Ci} / \mathrm{mmole}$ )] and Sarkosyl [final concentration, $0.5 \%$ ) were added to the washed complexes, and the incubation continued for $30 \mathrm{~min}$ at $30^{\circ} \mathrm{C}$. Transcription was terminated and the runoff transcripts were analyzed as described (Arias and Dynan 1989). Phosphorylation assays were performed identically to transcription assays, except that the initiation reaction was for $5 \mathrm{~min}$ in the presence of $\alpha-{ }^{32} \mathrm{P}$-labeled ATP $(60 \mathrm{Ci} / \mathrm{mmole})$, initiated complexes were washed only once and in the absence of Sarkosyl, and RNAP II was allowed to run off the template in the presence of nonradiolabeled elongation nucleotides. Radiolabeled proteins were immunoprecipitated using 8WG16 antibody and protein A-Sepharose as described previously (Arias et al. 1991).

\section{DNA-binding assay}

DNA binding was analyzed by incubating $50 \mathrm{ng}$ of purified fusion proteins with the GAL4 recognition oligonucleotide described above, which was 5 -end-labeled using $\left[\gamma^{-}{ }^{32} \mathrm{P}\right]$ ATP. Incubation was for $15 \mathrm{~min}$ at room temperature in a reaction mixture that contained $200 \mathrm{pg}$ of probe and $100 \mathrm{ng}$ of poly[d(I-C)] in $0.5 \times \mathrm{TZ}$ buffer. Mobility-shifted complexes were identified by nondenaturing gel electrophoresis using a $5 \%$ polyacrylamide gel. Competitive binding assays were performed using a nonradioactive GAL4 consensus recognition oligonucleotide or an unrelated oligonucleotide with sequence 5 '-GATCTCCACCAAGAACCATTTCCTA-3' and its complement 5'-GATCTAGGAAATGGGTGGTTCTTGGTGGA-3' .

\section{Elution of protein kinase from DNA beads and kinase assays}

Protein complexes were formed by incubating AdUAS or AdMLP DNA beads with HeLa nuclear extract for $60 \mathrm{~min}$ at $30^{\circ} \mathrm{C}$. A typical experiment used $25 \mu$ l of DNA beads [1 : 1 (vol/ vol) slurry in water, $500 \mathrm{ng}$ of DNA per reaction] and $25 \mu \mathrm{l}$ of nuclear extract. Complexes were washed three times with TX buffer containing $0.25 \mathrm{M} \mathrm{KCl}$ and twice with TX buffer containing $0.05 \mathrm{M} \mathrm{KCl}$. CTD kinase activity was eluted by adding $\mathrm{KCl}$ to a final concentration of $1 \mathrm{M}$ and incubating the mixture for 5 min at $30^{\circ} \mathrm{C}$. The eluant was separated from the DNA beads by centrifugation and adjusted to $50 \mathrm{~mm} \mathrm{KCl}$ by dilution in TX buffer, unless otherwise noted in the figure legends.

Phosphorylation of the CTD fusion proteins G147 and GST was typically assayed in TX buffer containing $2 \mu \mathrm{l}$ of the diluted eluant, $100 \mathrm{ng}$ of fusion protein, $1 \mathrm{ng}$ of DNA fragment, $0.05 \mathrm{M}$ 
$\mathrm{KCl}$, and $12.5 \mu \mathrm{M}\left[\gamma^{-32} \mathrm{P}\right] \mathrm{ATP}$ (4 Ci/mmole) in a final volume of $50 \mu \mathrm{l}$. Samples were incubated at $30^{\circ} \mathrm{C}$ for $30 \mathrm{~min}$ or as specified in the figure legends. Samples were immunoprecipitated using $8 \mathrm{WG} 16$ antibody and protein A-Sepharose as described (Arias et al. 1991) or analyzed directly by SDS-PAGE as specified in the figure legends.

$\mathrm{CNBr}$ cleavage of $\mathrm{GCl} 147$ protein was carried out as described previously for RNA polymerase II (Arias et al. 1991).

\section{Isolation of DNA-PK}

DNA-PK was solubilized from a HeLa cell ribosomal pellet, chromatographed on DEAE-Sepharose CL-6B and doublestranded DNA cellulose, and rechromatographed on DEAESepharose in the presence of $\mathrm{MgCl}_{2}$ as described by Lees-Miller et al. (1990).

In the experiment in Figure 7, the DNA bead-eluted kinase was purified further using a Superdex-200 H16/160 column (Pharmacia) with a flow rate of $0.5 \mathrm{ml} / \mathrm{min}$ and a buffer containing $50 \mathrm{~mm}$ Tris- $\mathrm{HCl}(\mathrm{pH} 7.9), 0.3 \mathrm{M} \mathrm{KCl}, 1 \mathrm{~mm}$ EDTA, $1 \mathrm{~mm}$ DTT, $5 \%$ glycerol, $0.02 \%$ Tween 20 , and $1 \mu \mathrm{g} / \mathrm{ml}$ each of PMSF, soybean trypsin inhibitor, pepstatin $\mathrm{A}$, and leupeptin.

\section{Acknowledgments}

We thank Stefanie Klug and Deborah McCulley for cell culture assistance, Michael Dahmus, Jeff Corden, and Danny Reinberg for communicating unpublished results, Ron Laskey for initially suggesting that the template-associated CTD kinase might be related to DNA-PK, Steve Jackson and Tim Carter for helpful discussions, and Rhea-Beth Markowitz and Thomas R. Cech for comments on the manuscript. This work was supported by the U.S. Public Health Service (grant GM 35866). A.D was a Fellow of the Israel Cancer Research Foundation. C.W.A. was supported by the Office of Health and Environmental Research of the U.S. Department of Energy.

The publication costs of this article were defrayed in part by payment of page charges. This article must therefore be hereby marked "advertisement" in accordance with 18 USC section 1734 solely to indicate this fact.

\section{References}

Ahearn, J.M. Jr., M.S. Bartolomei, M.L. West, L.J. Cisek, and J.L. Corden. 1987. Cloning and sequence analysis of the mouse genomic locus encoding the largest subunit of RNA polymerase II. I. Biol. Chem. 262: 10695-10705.

Allison, L.A. and C.J. Ingles. 1989. Mutations in RNA polymerase II enhance or suppress mutations in GAL4. Proc. Natl. Acad. Sci. 86: 2794-2798.

Allison, L.A., M. Moyle, M. Shales, and C.J. Ingles. 1985. Extensive homology among the largest subunits of eukaryotic and prokaryotic RNA polymerases. Cell 42: 599-610.

Allison, L.A., J.K.C. Wong, V.D. Fitzpatrick, M. Moyle, and C.J. Ingles. 1988. The C-terminal domain of the largest subunit of RNA polymerase II of Saccharomyces cerevisiae, Drosophila melanogaster and mammals: A conserved structure with an essential function. Mol. Cell. Biol. 8: 321-329.

Arias, J.A. and W.S. Dynan. 1989. Promoter-dependent transcription by RNA polymerase II using immobilized enzyme complexes. J. Biol. Chem. 264: 3223-3229.

Arias, J.A., S.R. Peterson, and W.S. Dynan. 1991. Promoter-dependent phosphorylation of RNA polymerase II by a template-bound kinase. I. Biol. Chem. 266: 8055-8061.

Bartholomew, B., M.E. Dahmus, and C.F. Meares. 1986. RNA contacts subunits IIo and IIc in HeLa RNA polymerase II transcription complexes. J. Biol. Chem. 261: 14226-14231.

Bartolomei, M.S., N.F. Halden, C.R. Cullen, and J.L. Corden. 1988. Genetic analysis of the repetitive carboxy-terminal domain of the largest subunit of mouse RNA polymerase II. Mol. Cell. Biol. 8: 330-339.

Boyle, W.J., T. Smeal, L.H.K. Defize, P. Angel, J.R. Woodgett, M. Karin, and T. Hunter. 1991. Activation of protein kinase C decreases phosphorylation of c-Jun at sites that negatively regulate its DNA-binding activity. Cell 64: 573-584.

Buratowski, S., S. Hahn, L. Guarente, and P.A. Sharp. 1989. Five intermediate complexes in transcription initiation by RNA polymerase II. Cell 56: 549-561.

Cadena, D.L. and M.E. Dahmus. 1987. Messenger RNA synthesis in mammalian cells is catalyzed by the phosphorylated form of RNA polymerase II. J. Biol. Chem. 262: 1246812474.

Cai, H. and D.S. Luse. 1987. Transcription initiation by RNA polymerase II in vitro. I. Biol. Chem. 262: 298-304.

Carter, T., I. Vancurova, I. Sun, W. Lou, and S. DeLeon. 1990. A DNA activated protein kinase from HeLa cell nuclei. Mol. Cell. Biol. 10: 6460-6471.

Chen, Y.-R., S.P. Lees-Miller, P. Tegtmeyer, and C.W. Anderson. 1991. The human DNA-activated protein kinase phosphorylates Simian virus $40 \mathrm{~T}$ antigen at amino- and carboxyterminal sites. I. Virol. 65: 5131-5140.

Cisek, L.J. and J.L. Corden. 1989. Phosphorylation of RNA polymerase by the murine homologue of the cell cycle control protein CDC2. Nature 339: 679-684.

. 1991. Purification of two protein kinases that phosphorylate the repetitive carboxy terminal domain of eucaryotic RNA polymerase II. Methods Enzymol. 200: 301-325.

Conaway, R.C. and J.W. Conaway. 1988. ATP activates transcription initiation from promoters by RNA polymerase II in a reversible step prior to RNA synthesis. J. Biol. Chem. 263: 2962-2968.

Corden, J.L. 1990. Tails of RNA polymerase II. Trends Biochem. Sci. 15: 383-387.

Corden, J.L., D.L. Cadena, J.M. Ahearn, Jr., and M.E. Dahmus. 1985. A unique structure at the carboxyl terminus of the largest subunit of eucaryotic RNA polymerase II. Proc. Natl. Acad. Sci. 82: 7934-7938.

Dahmus, M.E. 1981. Phosphorylation of eukaryotic DNA-dependent RNA polymerase. J. Biol. Chem. 256: 3332-3339.

Dahmus, M.E. and W.S. Dynan. 1992. Phosphorylation of RNA polymerase II as a transcriptional regulatory mechanism. In Transcriptional regulation (ed. S.L. McKnight and K. Yamamoto|, Cold Spring Harbor Laboratory Press, Cold Spring Harbor, New York.

Feaver, W.J., O. Gileadi, Y. Li, and R.D. Kornberg. 1991. CTD kinase associated with yeast RNA polymerase II initiation factor b. Cell 67: 1223-1230.

Flores, O., H. Lu, M. Killeen, J. Greenblatt, Z.F. Burton, and D. Reinberg. 1991. The small subunit of transcription factor IIF recruits RNA polymerase II into the preinitiation complex. Proc. Natl. Acad. Sci. 88: 999-1003.

Giniger, E., S.M. Varnum, and M. Ptashne. 1985. Specific DNA binding of GAL4, a positive regulatory protein of yeast. Cell 40: $767-774$.

Guilfoyle, T.J. 1989. A protein kinase from wheat germ that phosphorylates the largest subunit of RNA polymerase II. Plant Cell 1: 827-836.

Jackson, S.P., J.J. MacDonald, S. Lees-Miller, and R. Tjian. 1990. GC-box binding induces phosphorylation of Spl by a DNAdependent protein kinase Cell 63: 155-165.

Kim, W.-Y. and M.E. Dahmus. 1989. The major late promoter of 
adenovirus- 2 is accurately transcribed by RNA polymerase IIo, IIa and IIb. J. Biol. Chem. 264: 3169-3176.

Laughon, A. and R.F. Gesteland. 1984. Primary structure of the Saccharomyces cerevisiae GAL4 gene. Mol. Cell. Biol. 4: 260-267.

Laybourn, P.J. and M.E. Dahmus. 1989. Transcription-dependent structural changes in the C-terminal domain of mammalian RNA polymerase subunit IIa/o. I. Biol. Chem. 264: 6693-6698.

- 1990. Phosphorylation of RNA polymerase IIa occurs subsequent to interaction with the promoter and before the initiation of transcription. J. Biol. Chem. 265: 13165-13173.

Lee, J.M. and A.L. Greenleaf. 1989. A protein kinase that phosphorylates the C-terminal repeat domain of the largest subunit of RNA polymerase II. Proc. Nat1. Acad. Sci. 86: 3624 3628.

- 1991. CTD kinase large subunit is encoded by CTK1, a gene required for normal growth of Saccharomyces cerevisiae. Gene Expression 1: 149-167.

Lees-Miller, S.P. and C.W. Anderson. 1989. The human doublestranded DNA-activated protein kinase phsophorylates the 90-kD heat-shock protein, HSP90 $\alpha$ at two $\mathrm{NH}_{2}$-terminal threonine residues. J. Biol. Chem. 264: 17275-17280.

Lees-Miller, S.P., Y.-R. Chen, and C.W. Anderson. 1990. Human cells contain a DNA-activated protein kinase that phosphorylates simian virus $40 \mathrm{~T}$ antigen, mouse p53, and the human Ku antigen. Mol. Cell. Biol. 10: 6472-6481.

Lin, Y.-S., M.F. Carey, M. Ptashne, and M.R. Green. 1988. GAL4 derivatives function alone and synergistically with mammalian activators in vitro. Cell 54: 659-664.

Lu, H., O. Flores, R. Weinmann, and D.L. Reinberg. 1991. The nonphosphorylated form of RNA polymerase II preferentially associates with the preinitiation complex. Proc. Natl. Acad. Sci. 88: 1004-1008.

Matsushima, N., C.E. Creutz, and R.H. Kretsinger. 1990. Polyproline, $\beta$-turn helices. Novel secondary structures proposed for the tandem repeats within rhodopsin, synaptophysin, synexin, gliadin, RNA polymerase II, hordein, and gluten. Proteins: Structure, Function, Genet. 7: 125-155.

Nonet, M.L. and R.A. Young. 1989. Intragenic and extragenic suppressors of mutations in the heptapeptide repeat domain of Saccharomyces cerevisiae RNA polymerase II. Genetics 123: 715-724.

Nonet, M., D. Sweetser, and R.A. Young. 1987. Functional redundancy and structural polymorphism in the large subunit of RNA polymerase II. Cell 50: 909-915.

Payne, J.M., P.J. Laybourn, and M.E. Dahmus. 1989. The transition of RNA polymerase II from initiation to elongation is associated with phosphorylation of the carboxy-terminal domain of subunit IIa. J. Biol. Chem. 264: 19621-19629.

Peterson, C.L., W. Kruger, and I. Herskowitz. 1991. A functional interaction between the C-terminal domain of RNA polymerase II and the negative regulator Sin-1. Cell 64: 11351143.

Raychaudhuri, P., S. Bagchi, and J.R. Nevins. 1989. DNA-binding activity of the adenovirus induced E4F transcription factor is regulated by phosphorylation. Genes \& Dev. 3: 620627.

Scafe, C., D. Chao, J. Lopes, J.P. Hirsch, S. Henry, and R.A. Young. 1990. RNA polymerase II C-terminal repeat influences response to transcriptional enhancer signals. Nature 347: 491-494.

Shirakawa, F. and S.B. Mizel. 1989. In vitro activation and nuclear translocation of NF-kB catalyzed by cyclic AMP-dependent protein kinase and protein knase C. Mol. Cell. Biol. 9: 2424-2430.
Sigler, P.B. 1988. Acid blobs and negative noodles. Nature 333: $210-212$.

Smith, D.B. and K.S. Johnson. 1988. Single-step purification of polypeptides expressed in Escherichia coli as fusions with glutathione S-transferase. Gene 67: 31-40.

Sorger, P.K. and H.R.B. Pelham. 1988. Yeast heat shock factor is an essential DNA binding protein that exhibits temperature dependent phosphorylation. Cell 54: 855-864.

Stevens, A. and M.K. Maupin. 1989. 5,6-dichloro-1- $\beta$ ribofuranosyl benzimidazole inhibits a HeLa protein kinase that phosphorylates an RNA polymerase II derived peptide. Biochem. Biophys. Res. Comm. 159: 508-515.

Suzuki, M. 1990. The heptad repeat in the largest subunit of RNA polymerase II binds by intercalating into DNA. Nature 344: 562-565.

Thompson, N.E., T.H. Steinberg, D.B. Aronson, and R.R. Burgess. 1989. Inhibition of in vivo and in vitro transcription by monoclonal antibodies prepared against wheat germ RNA polymerase II that react with the heptapeptide repeat of eukaryotic RNA polymerase II. $I$. Biol. Chem. 264: 1151111520.

Thompson, R.C. 1988. EFTu provides an internal kinetic standard for translational accuracy. Trends Biochem. Sci. 13: 9193

Van Dyke, M.W., R.G. Roeder, and M. Sowodogo. 1988. Physical analysis of transcription preinitiation complex assembly on a class II gene promoter. Science 241: 1335-1338

Walker, A.I., T. Hunt, R.J. Jackson, and C.W. Anderson. 1985. Double-stranded DNA induces the phosphorylation of several proteins including the $90,000 \mathrm{~mol}$. wt. heat-shock protein in animal cell extracts. EMBO J. 4: 139-145.

Zehring, W.A., J.M. Lee, J.R. Weeks, R.S. Jokerst, and A.L. Greenleaf. 1988. The C-terminal repeat domain of RNA polymerase II largest subunit is essential in vivo, but is not required for accurate transcriptional initiation in vitro. Proc. Natl. Acad. Sci. 85: 3698-3702.

Zhang, J. and J.L. Corden. 1991a. Identification of phosphorylation in the repetitive carboxyl terminal domain of the mouse RNA polymerase II largest subunit. $/$. Biol. Chem. 266: 2290-2296.

- 1991b. Phosphorylation causes a conformational change in the carboxyl terminal domain of the mouse RNA polymerase II largest subunit. I. Biol. Chem. 266: 2297-2302. 


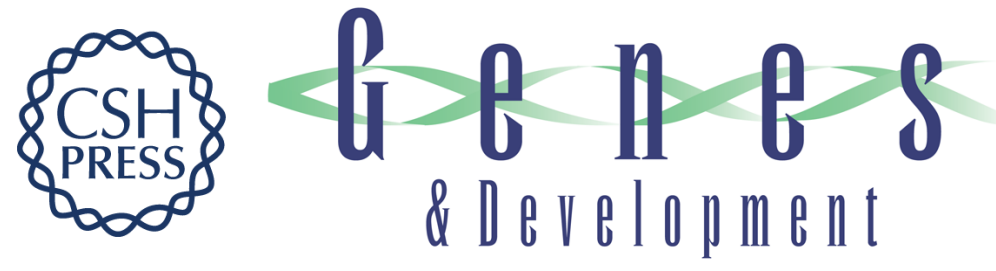

\section{DNA binding provides a signal for phosphorylation of the RNA polymerase II heptapeptide repeats.}

S R Peterson, A Dvir, C W Anderson, et al.

Genes Dev. 1992, 6:

Access the most recent version at doi:10.1101/gad.6.3.426

References This article cites 55 articles, 33 of which can be accessed free at:

http://genesdev.cshlp.org/content/6/3/426.full.html\#ref-list-1

License

Email Alerting

Service

Receive free email alerts when new articles cite this article - sign up in the box at the top right corner of the article or click here.

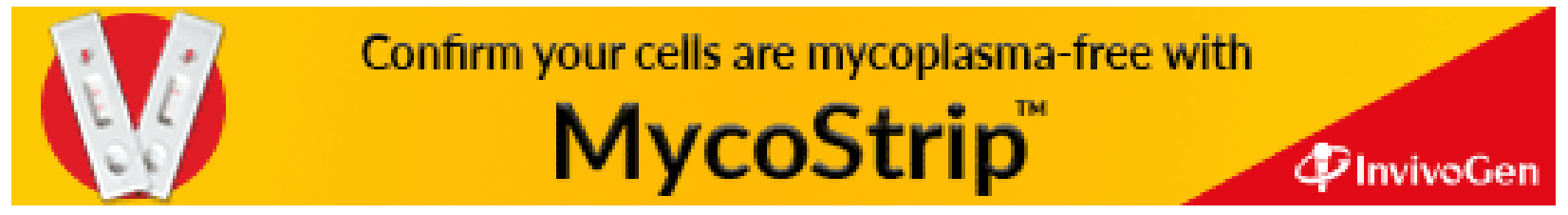

